Journal of Development and Social Change, Vol. 3, No. 1, April 2020

p-ISSN 2614-5766, https://jurnal.uns.ac.id/jodasc

\title{
PERAN GANDA WANITA DALAM EKONOMI KELUARGA (Studi Kasus Pada Pedagang Wanita Pasar Klewer)
}

\author{
Bachtiar Suryo Bawono ${ }^{1}$, Bambang Santosa ${ }^{2}$ \\ Program Studi Sosiologi Fakultas Ilmu Sosial dan Politik \\ Universitas Sebelas Maret Surakarta Indonesia \\ Email1: bachtiar.bawono@student.uns.ac.id,Email²: bambangsantosa59@gmail.com
}

\begin{abstract}
Women in the era of globalization have experienced significant changes. As women who previously were not played an active role in the labor market, many woman now play an active role in the world of work, especially in the trade sector. Based on data from the Surakarta City Gender Study and Social Workers Association (PRP) Study, 72\% of the traditional market trader population is women. In addition to having a positive impact, increasing women's participation in the world of work also has a negative impact on women themselves. As women as workers will experience double burden problems. It means women who work will have two responsibilities, that is public work responsibilities and domestic work responsibilities.

Therefore, the author would like to know how the Dual Role of Women in the Family Economy in Women's Traders' Families in Surakarta City's Klewer Market? This study uses gender analysis techniques Hardvard-1 or HAF method combined with interactive analysis methods. The results showed that the first category of informants only wives who traded in the market showed that, the wife played a role in increasing family income. The initial income of a husband working alone is only able to meet primary needs. After the wife trades, the husband and wife can meet secondary needs and increase family purchasing power. In the access and control of family economic resources, they tend to be dominated by husbands. The informants of both husband and wife trading together in a kios then the role of the wife does not affect the ups and downs of trading income. In accessing and controlling economic resources the family runs in balance.
\end{abstract}

Keywords: gender, dual roles, HAF analysis

Abstrak: Perempuan dalam era globalisasi telah banyak mengalami perubahan secara signifikan. Di mana perempuan yang sebelumnya tidak cukup berperan aktif dalam pasar kerja, kini banyak perempuan yang turut berperan aktif dalam dunia kerja terutama pada sektor perdagangan. Berdasarkan data Kajian Studi Gender dan Social Perhimpunan Rakyat Pekerja (PRP) Kota Surakarta menunjukkan bahwa $72 \%$ populasi pedagang pasar tradisional adalah perempuan. Selain memberikan dampak positif, peningkatan peran serta perempuan dalam dunia kerja juga memberikan dampak negatif bagi perempuan itu sendiri. Di mana perempuan sebagai pekerja akan mengalami permasalahan beban ganda. Artinya perempuan yang berkerja akan mempunyai dua tanggungjawab yaitu tangungjawab pekerjaan publik dan tanggungjawab pekerjaan rumah tangga. 
Oleh karena itu, penulis ingin mengetahui bagaimana Peran Ganda Wanita dalam Ekonomi Keluarga pada Keluarga Pedagang Wanita di Pasar Klewer Kota Surakarta ? Penelitian ini menggunakan teknik analisis gender metode Hardvard-1 atau HAF yang dipadukan dengan metode analisis interaktif. Hasil penelitian menunjukkan bahwa informan kategori pertama hanya istri yang berdagang di pasar menunjukkan bahwa, istri berperan dalam menambah penghasilan keluarga. Penghasilan awal suami bekerja seorang diri hanya mampu untuk mencukupi kebutuhan primer. Setelah istri berdagang, suami istri dapat memenuhi kebutuhan sekunder dan meningkatkan daya beli keluarga. Dalam akses dan kontrol sumber daya ekonomi keluarga, cenderung didominasi oleh suami. Informan kedua suami istri berdagang bersama dalam satu kios menunjukkan bahwa, peran istri tidak mempengaruhi naik dan turunnya penghasilan berdagang. Dalam akses dan kontrol sumber daya ekonomi keluarga berjalan seimbang.

Kata kunci: gender, peran ganda, analisis HAF

\section{PENDAHULUAN}

Dalam dunia globalisasi kesetaraan gender menjadi fokus bagi seluruh elemen masyarakat. Cara pandang terhadap laki-laki dan perempuan sudah mulai bergeser secara perlahan-lahan. Laki-laki dan perempuan harus dapat memiliki hak yang sama dalam melakukan aktivitas publik ataupun domestik. Perempuan berhak untuk melakukan kegiatan publik agar mereka juga dapat memperoleh penghasilan. Wanita yang telah berkeluarga sangat susah jika masih dibatasi pergerakannya.

Perempuan pintar menjajakan produk dagangan, melakukan kegiatan berdagang untuk menarik pembeli dan cermat mengkalkulasi laba rugi dalam berdagang. Hal ini nampak pada sebuah data kajian yang pernah dilakukan oleh Perhimpunan Rakyat Pekerja (PRP) Solo. Data Kajian Studi Gender dan Social Perhimpunan Rakyat Pekerja (PRP) Solo menunjukkan fakta, mayoritas utama dalam aktivitas social ekonomi di berbagai pasar tradisional di Indonesia $67 \%$ adalah perempuan. Perempuan sebagai pedagang, penjual, dan pembeli. Dari populasi pedagang pasar tradisional, $72 \%$ adalah perempuan. Dengan paparan diatas dapat dilihat peran wanita dalam aktivitas pasar cukup besar. Dengan demikian kawasan pasar menjadi lingkungan yang dipenuhi oleh para wanita. Khususnya mereka yang telah berkeluarga, membantu suami dalam mencari nafkah. (m.tribunnews.com)

Dewasa ini telah banyak dijumpai perempuan yang terlibat di sektor publik. Masyarakat mulai memandang positif aktivitas perempuan di sektor publik. Karena selain merupakan manifestasi persamaan hak laki-laki dan perempuan, aktivitas perempuan di sektor publik juga dapat memberi keuntungan finansial bagi keluarga. Berdasarkan hasil pengukuran GDI (Gender-related Development Index)- Indeks Pembangunan Gender tahun 2010-2015 antar kabupaten/kota di Provinsi Jawa Tengah prosentase angkatan kerja perempuan di Kota Surakarta mencapai angka 96,48\% lebih tinggi dibandingkan dengan capaian Kota lainnya di Jawa Tengah seperti Kota Semarang, Kota Salatiga, Kota 
Pekalongan, dan Kota Magelang adalah yang paling tinggi. (www.jdih.setjen.kemendagri.go.id)

Pada kehidupan rumah tangga masyarakat saat ini, cukup sulit jika hanya mengandalkan pendapatan dari suami. Tujuan dari sebuah keluarga selain keharmonisan adalah kesejahteraan pada ekonomi keluarga. Kesejahteraan ekonomi keluarga menjadi fokus utama dalam keluarga agar dapat mencapai kehidupan yang layak. Kehidupan yang layak akan terlihat dari tercukupinya kebutuhan pokok serta kebutuhan tambahan lainnya. Oleh karena itu keluarga harus bekerja agar dapat memenuhi kebutuhannya. Kebutuhan yang semakin bervariatif serta harga kebutuhan yang melonjak setiap tahunnya tidak akan tercukupi jika hanya mengandalkan penghasilan suami. Terlebih pada masa kemajuan teknologi kebutuhan hidup tidak hanya bahan pokok dan biaya sekolah. Namun juga biaya untuk kelancaran berkomunikasi serta mengakses banyak hal. Oleh karena itu dibutuhkan peran wanita dalam meningkatkan ekonomi keluarga.

\section{METODE PENELITIAN}

Terdapat 3000 lebih pedagang di Pasar Klewer Surakarta yang terdiri dari 2211 perdagangan yang memiliki stan dan 765 pedagang oprokan. Pedagang oprokan merupakan istilah bagi pedagang yang tidak memiliki stan. Selain kedua jenis pedagang tersebut terdapat pedagang mobil yang baru-baru ini membuka lapak di Pasar Klewer Surakarta. Penelitian ini menggunakan jenis penelitian kualitatif dengan pendekatan studi kasus. Penelitian ini menggunakan pendekatan studi kasus karena ingin mengetahui secara lebih jelas bagaimana peran wanita dalam ekonomi keluarga. Teknik pengumpulan data dilakukan dengan secara Observasi, wawancara, kemudian dokumentasi.

Kerangka analisis gender merupakan kerangka analisis dasar yang sifatnya masih sederhana. Kerangka ini merupakan suatu jaringan (grid) atau matriks untuk mengumpulkan data di tingkat mikro (komunitas atau rumah tangga). Dalam kaitannya dengan penelitian ini kerangka analisis gender model Harvard-1 atau HAF akan dipakai untuk menganalisa peranan perempuan dan laki-laki dalam aktivitasnya sebagai mitra dalam kerja maupun keluarga. Kerangka analisis gender model Harvard-1 atau HAF merupakan proyek perumusan informasi untuk melihat sejauh mana perempuan terintegrasi dalam suatu aktivitas. Versi yang umum dari kerangka analisis gender model Harvard-1 atau HAF, baik di tingkat individu, keluarga atau rumah tangga, komunitas, ataupun lembaga dilakukan dengan mengajukan pertanyaan. Menurut Hunt yang juga diadaptasi oleh Overholt dalam kerangka analisis gender model Harvard-1 atau HAF, ada empat kategori analisis yang saling terkait :

1. Siapa melakukan apa? (pembagian kerja seksual)

2. Siapa memiliki apa? (akses dan kontrol sumber daya)

3. Faktor apa yang mempengaruhi pengaturan gender tersebut? (faktor yang mempengaruhi dan yang mungkin dipergunakan mengubah hubungan gender)

4. Siapa mendapat manfaat apa? 


\section{HASIL DAN PEMBAHASAN}

\section{Gambaran Umum Pasar Klewer Surakarta}

Pasar Klewer dirintis sejak jaman penjajahan Jepang, dimana kehidupan warga Surakarta banyak mengalami kesulitan. Berawal dari kehidupan yang serba sulit ini kemudian sejumlah orang berinisiatif untuk berjualan pakaian dan kain. Pemerintah kemudian merenovasi pasar hingga mencapai bentuk seperti yang sekarang ini, dengan pelaksana PT. Sahid yang bermitra dengan Bank Bumi Daya. Peresmiannya dilakukan oleh Presiden Soeharto pada 7 Juni 1971dengan nama tetap Pasar Klewer.Sejalan dengan pertumbuhan dan perkembangan ekonomi, keberadaan pasar Klewer semakin dikenal sebagai pust tekstil di Jawa Tengah.

Secara geografis Pasar Klewer terletak di kelurahan Gajahan, kecamatan Pasar Kliwon, tepatnya di sebelah selatan masjid agung atau di sebelah Barat Gapura Kraton Kasunanan Surakarta. Luas pasar Klewer barat kurang lebih 135 X 65 meter, yang terdiri dari dua lantai ditambah dengan pasar Klewer timur kurang lebih seluas 85 X $65 \mathrm{~m}$. Terdapat 2064 toko/kios/los yang dihuni oleh kurang lebih 1755 pedagang (resmi).Pasar Klewer yang baru saat ini memiliki fasilitas yang lebih lengkap. Sekarang terdapat lift dan eskalator yang memudahkan para pengunjung dan pedagang untuk melakukan transaksi di pasar tersebut.

Namun bersamaan dengan fasilitas yang lebih lengkap tersebut, luas kios di Pasar Klewer dengan wajah baru ini mengalami penyempitan. Yang semula 3 x 5 meter persegi, sekarang menjadi 2,60 x 4,50 meter persegi. Di tambah lagi dengan adanya pilar penyangga bangunan sehingga luas kios menjadi lebih kecil lagi.Namun dengan begitu, diharapkan pasar yang termasuk tradisional ini mampu bersaing dengan pasar-pasar modern dan membuat para pengunjung terus merasa nyaman berbelanja di dalamnya.

\section{Aktivitas Berdagang di Pasar}

Profil kegiatan menunjukkan jenis-jeis kegiatan berupa produksi yakni kegiatan yang dijadikan sebagai sumber ekonomi atau penghasilan keluarga dan reproduksi yang berkaitan dengan urusan domestik keluarga. Pembagian kerja merujuk pada ada tidaknya pembagian kerja yang didasarkan atas gender atau berdasarkan jenis kelamin dalam keluarga wanita pedagang di Pasar Klewer. Profil kegiatan dan pembagian kerja akan menggambarkan secara lebih dekat kondisi atau situasi nyata dalam keluarga wanita pedagang di Pasar Klewer terkait dengan peran ganda yang ditangguhkan kepada wanita pedagang.

Profil kegiatan dan pembagian kerja dalam keluarga wanita pedagang di Pasar Klewer meliputi kegiatan produksi/publik, reproduksi/domestik, dan kegiatan sosial. Di dalam masyarakat, masih terdapat peran ganda yang harus diemban oleh wanita berumah tangga. Peran sebagai ibu rumah tangga sangat melekat dalam diri wanita berkeluarga. Pembagian kerja yang dilaksanakan oleh beberapa keluarga khususnya wanita yang bekerja sering mengalami ketimpangan. Ini dapat dilihat dari beban kerja yang dilakukan oleh wanita sebagai ibu rumah tangga dan seorang pekerja. Disampinng memiliki tanggung jawab pekerjaan rumah tangga, wanita masih melakukan kegiatan produktif/ publik demi menyambung hidup keluarga mereka. 
Seperti yang terjadi pada keluarga wanita pedagang di Pasar Klewer yang kesehariannya masih ditanggungkan pada beban peran ibu rumah tangga. Mereka harus pandai dalam mengatur waktu agar semua pekerjaan yang dilakukan berjalan dengan baik. Peran ganda yang mereka pikul membuat para pedagang wanita di Pasar Klewer harus pandai dalam beradaptasi. Tuntutan ekonomi mendesak pedagang wanita untuk keluar dari wilayah domestik yang sering menggambarkan anggapan masyarakat terhadap kaum mereka ke arah kegiatan publik atau produktif. Penghasilan dari suami dirasa tidak cukup untuk memenuhi kebutuhan selain primer. Keinginan untuk mendapatkan penghasilan yang lebih demi kesejahteraan ekonomi keluarga menjadi motivasi para pedagang wanita untuk merasakan kegiatan produktif/ publik. Karena bagi mereka kehidupan ini tidak hanya tentang kecukupan untuk makan sehari-hari. Biaya sekolah yang mulai meninggi serta keinginan untuk bisa meningkatkan daya beli keluarga juga menjadi faktor mereka membantu suami dalam menambah pendapatan keluarga.

\section{Aktivitas Dalam Mengelola Sumber Daya Ekonomi Keluarga}

YKAB Surakarta memang berbeda dengan sekolah pada umumnya, karena di dalam SLB/A YKAB juga memberikan perhatian, pengertian, dan kasih sayang kepada murid-murid yang berada di sana, karena selain memberikan pelajaran umum, para pembina juga memberikan sebuah peran keluarga seperti memberikan pendidikan agama, melatih keterampilan dan hobi mereka yang mungkin tidak mereka (murid-murid) dapatkan di dalam keluarga.

Di sisi lain, pemberian perhatian, kasih sayang dan peran keluarga pun tidak hanya diberikan oleh para pembina atau guru yang mengajar para murid saja di dalam kelas, pemberian perhatian dan kasih sayang layaknya orang tua kandung mereka (murid-murid) pun juga diberikan oleh seorang ibu yang bertugas menjaga mereka setiap saat, peran dari seorang Ibu tersebut adalah menjaga tempat tinggal mereka atau asrama dan mengurusi segala keperluan mereka kecuali untuk keperluan pribadi setiap murid, beliau lah yang membangunkan murid-murid di pagi hari, yang memasak makanan untuk para murid setiap hari nya untuk makan pagi, makan siang, dan makan malam, tanpa lelah dan memang sudah tuntutan profesi beliau menjalani nya, selain itu beliau juga merasa kasian dan ikut merasakan apa yang murid-murid rasakan dengan keterbatasan yang mereka miliki.

\section{Strategi Dalam Memanfaatkan Potensi Keluarga}

Faktor-faktor yang mempengaruhi kegiatan, akses dan kontrol informan dalam keluarga menunjukkan faktor-faktor yang menimbulkan perbedaan kesempatan dan penikmatan hasil-hasil kegiatan perempuan. Faktor-faktor yang mempengaruhi kegiatan, akses dan kontrol dalam keluarga wanita pedagang terkait dengan perbedaan kondisi antara suami dan istri. Faktor-faktor yang mempengaruhi kegiatan, akses dan kontrol dalam keluarga wanita pedagang hanya istri berdagang di pasar berbeda dengan keluarga wanita pedagang istri dan suami berdagang di pasar.

Faktor-faktor yang mempengaruhi kegiatan, akses dan kontrol dalam keluarga wanita pedagang suami istri berdagang di pasar berbeda dengan keluarga wanita pedagang istri dan 
suami berdagang di pasar. Didalam keluarga wanita suami istri berdagang bersama masih dibagi menjadi dua macam. Yaitu dengan akses dan kontrol seimbang dengan yang terjadi ketimpangan.

\section{Siklus Kegiatan Responden}

Dimensi ini secara khusus menjelaskan tentang dampak yang timbul dan siklus kegiatan dan pembagian kerja, akses dan kontrol terhadap sumber daya ekonomi dalam keluarga wanita pedagang di Pasar Klewer. Fokus utama dari diskusi ini adalah untuk mengetahui bagaimana peran wanita dalam perekonomian keluarga pada wanita pedagang di Pasar Klewer Surakarta. Gender menjadi sebuah konsep yang menjelaskan tentang sifat yang melekat pada kaum laki-laki dan perempuan yang dikontruksikan secara sosial maupun kultural. Pada hakekatnya, hal-hal yang berupa ciri-ciri dan sifat-sifat yang dapat ditukarkan merupakan konsep gender.

Persepsi setiap wanita pakerja maupun ibu rumah tangga terhadap peristiwa yang dialami dari lingkungannya tidak jauh berbeda satu dengan yang lainnya. Wanita sebagai salah satu obyek yang sering termarginalkan dalam masyarakat. Masyarakat menganggap bahwa wanita tidak dapat menghasilkan pundi-pundi rupiah. Kegiatan wanita dibatasi karena pandangan masyarakat terhadap wanita dianggap lemah dan emosional. Wanita dipandang sebelah mata oleh masyarakat mengenai perannya dalam membantu ekonomi keluarga. Bahkan karena kuatnya budaya patriarki membuat wanita menjadi tidak dipercaya untuk andil dalam kegiatan publik. Ini banyak terjadi didalam masyarakat pedesaan yang jauh dari hiruk pikuk kota. Karena pola pikir masyarakat desa hanya sebatas memenuhi kebutuhan pokok bisa tercukupi. Namun di kota seperti Surakarta, ekonomi keluarga menjadi tanggung jawab suami dan istri. Variasi kebutuhan keluarga yang semakin banyak menjadi alasan utama mengapa desakan ekonomi di kota menjadi lebih terasa. Kebutuhan masyarakat perkotaan tidak hanya pemenuhan kebutuhan pokok. Sempitnya lapangan pekerjaan dan padatnya aktivitas masyarakat menjadi tingkat stres masyarakat meningkat. Akibatnya masyarakat membutuhkan waktu untuk berlibur bersama keluarga. Gaya hidup masyarakat kota berbeda dengan masyarakat desa. Sehingga banyak dijumpai pada masyarakat perkotaan, wanita ikut bekerja demi meningkatkan ekonomi keluarga.

\section{PENUTUP}

Pada pembahasan diatas terdapat konsep yang dapat disimpulkan oleh penulis mengenai bagaimana peran wanita dalam ekonomi keluarga. Peran wanita dalam ekonomi keluarga dapat menambah penghasilan keluarga ketika hanya istri yang berdagang. Namun pada keluarga yang melakukan kegiatan berdagang suami dan istri dalam satu kios, maka peran istri cenderung tidak berpengaruh dalam menambah penghasilan keluarga. Penulis merumuskan empat konsep untuk menyimpulkan permasalahan yang telah dijabarkan. Konsep pertama yaitu analisis profil kegiatan pedagang, analisis akses dan kontrol sumber daya dan manfaat, analisis faktor-faktor mempengaruhi akses dan kontrol, analisis siklus 
kegiatan. Dari empat konsep tersebut penulis dapat menyimpulkan melalui poin-poin yang diambil dari penjabaran pada isi penelitian.

Terdapat tiga profil kegiatan yang penulis rumuskan dalam kegiatan pada keluarga pedagang di Pasar Klewer Surakarta. Profil kegiatan keluarga pedagang yang menjadi informan penulis menunjukkan bahwa kegiatan publik atau pekerjaan yang digeluti informan utama adalah pedagang wanita yang berada di Pasar Klewer Surakarta. Kegiatan publik atau pekerjaan pada informan pendukung meliputi pedagang yang bersama istri berjualan bersama di Pasar Klewer Surakarta, pegawai negeri sipil, karyawan swasta, dan wiraswasta. Dalam kegiatan domestik atau reproduktif meliputi kegiatan memasak, mencuci, mengasuh anak, membersihkan rumah dan lain sebagainya. Kegiatan ketiga yang diikuti macamnya yaitu sosial politik seperti pengajian, PKK, organisasi dan andil dalam kader partai politik.

Penulis dapat mengetahui pembagian peran dalam keluarga pedagang pasar Klewer itu seimbang atau tidak. Pada keluarga pedagang hanya istri yang melakukan kegiatan berdagang, akses dan kontrol cenderung lebih di dominasi oleh suami. Berbeda pada keluarga yang suami istri berdagang bersama dalam satu kios. Akses dan kontrol dalam kegiatan berdagang maupun domestik dapat berjalan dengan seimbang. Selain itu, peneliti menemukan bahwa pola pembagian akses dan kontrol pada kegiatan domestik antara suami dan istri yang berdagang bersama, digunakan sebagai sebuah acuan ketika mereka mengelola pembagian akses dan kontrol dalam berdagang. Hasil penelitian menunjukkan sebagian besar informan terhambat oleh faktor budaya patriarki dan nilai-nilai agama ketika ikut serta dalam kegiatan publik atau berdagang. Namun karena dorongan dari faktor desakan ekonomi keluarga, suami harus merelakan istri bekerja agar ekonomi keluarga tetap stabil.

\section{DAFTAR PUSTAKA}

Argyo Demartoto, Menyibak Sensitivitas Gender dalam Keluarga Difabel. Cetakan 1. Surakarta LPP UNS dan UNS Press. 2007

Miles, MB dan Huberman, A.M, Analisis Data Kualitatif, Buku Sumber tentang http://www.jdih.setjen.kemendagri.go.id/files/Kota_Surakarta_9_2016.

https://m.tribunnews.com 